\title{
RESIDUAL STRENGTH ANALYSIS USING CTOA CRITERIA FOR FUSELAGE STRUCTURES CONTAINING MULTIPLE SITE DAMAGE
}

Ching-long Hsu, Jeffery J. Tom, Brett L. Anderson, The Boeing Company, USA

\section{ABSTRACT}

An extensive research program was conducted by the Boeing Company under the funding of the Federal Aviation Administration (FAA), National Aeronautics and Space Administration (NASA), and the United States Air Force Research Laboratory (USAF/RL) to investigate the effects of multiple-site damage (MSD) on the residual strength of several types of fuselage splice joints. Under this program, a series of experiments were conducted for validation of the analytical tools. The test specimens consisted of large flat panels, curved panels, and an aft pressure bulkhead. The flat panel specimens included three types of typical fuselage longitudinal splice joints and one type of circumferential splice joint. The curved panels were tested under simulated loads of combined cabin pressure and fuselage down bending. Two fuselage skin splice types were tested. A section of an aft fuselage containing a large lead crack and MSD in the pressure dome was also tested to demonstrate the capabilities of the methodologies in analyzing actual aircraft structures. This paper presents the analytical approaches using Crack-Tip-Opening-Angle (CTOA) fracture criterion and the comparison of predictions with the experimental results in terms of crack linkup stress and residual strength.

\section{INTRODUCTION}

Fatigue cracks can develop in high-time aircraft structures, usually in the areas of stress concentration. Cracks that form along a continuous line of fasteners, as at a joint or splice, or in a repetitive structure detail under similar loading, are commonly known as multi-sitedamage (MSD). Previous studies have shown that these small cracks, when present, can significantly reduce the load-carrying capability of the structure [1]. Using CTOA fracture criterion in the STAGS [2] code was found to be an efficient and accurate way to predict the residual strength of complicated splice joints containing MSD. The CTOA fracture criterion was evolved from the critical crack-tip opening displacement (CTOD) concept developed by Wells [3]. This criterion assumes that stable crack growth will occur when an angle formed by a point on the upper surface of a crack (at a fixed distance behind the crack-tip), the crack-tip itself, and a point on the lower surface (again at a fixed distance behind the crack-tip), reaches a "critical" angle, $\Psi_{c}$. As the crack grows, a plastic zone behind the crack tip unloads to an elastic state leaving a plastic wake behind the advancing crack tip. This results in a smaller CTOA after crack growth. Further increase of the applied load is needed to make CTOA reach that critical angle and thus to cause further crack growth. The material therefore appears to become tougher as the crack grows. Considerable researches on CTOA have been done at NASA[4-8]. The CTOA is found to be a mild function of the distance $d$. NASA suggested that a characteristic distance of $1 \mathrm{~mm}$ should be used for $d$. The distance is selected such that there is a consistency between experimental measurements and analyses. The critical CTOA, $\Psi_{c}$, can be determined directly by measuring the crack tip opening angle or indirectly using finite element analysis to find a critical CTOA that can best match the experimental results. NASA also suggests that the width of the plane strain material, or the core height, around the crack tips should be set equal to the thickness of the skin to simulate the thickness constraint at the crack tips. Plane stress elements were used for the rest of the model. 


\section{RESIDUAL STRENGTH STUDY OF FLAT PANELS WITH MSD}

Four types of fuselage splice joints were constructed for residual strength tests as shown in Figure 1. The overall dimension of the test panels were $1219 \mathrm{~mm}$ wide by $2340 \mathrm{~mm}$ long. Type 1 splice joint represents a lap joint with two thin layers of fingered doublers sandwiched between two sheets of skin and between the skin and the longeron. Type 2 splice joint represents a simple lap joint with three rows of fasteners. Type 3 splice joint represents a butt joint with strips of internal and external doublers under an I-shape splicing longeron. Type 4 splice joint represents a circumferential butt joint with a thin internal fingered doubler and a thicker doubler plate. The skins were made of clad 2024-T3 aluminum sheet, the doublers were made of 7075-T6 sheets, and the longerons were made of 7075-T6511 aluminum sheet. Except for the type 4 splice joint, the grain of the skin was in the long-transverse direction. A lead crack approximately $325 \mathrm{~mm}$. to $376 \mathrm{~mm}$ long, depending on the joint type, was introduced in the critical rivet row with a fine jeweler's saw, and the tips of the sawcut were sharpened with diamond wires of approximately $1 \mathrm{~mm}$ to $1.5 \mathrm{~mm}$ diameter. For each splice type, two specimens contained only the large lead crack, and the other two specimens contained multiple small cracks in the fastener holes ahead of the large lead crack. The sizes of the MSD were $1.3 \mathrm{~mm}$ and $2.54 \mathrm{~mm}$, respectively. The MSD were introduced into the fastener holes prior to the installation of rivets.

The specimens were tested with the guide plates to avoid out-of-plane buckling. Displacement-controlled loading was applied to the lower edge of the specimens. The applied load and the measured crack length were recorded incrementally until panel failed completely. Fine-meshed finite element STAGS models were used to predict four types of joints. The critical CTOA, $\Psi_{c}$, for the 2024-T3 material is one of the most important variables in the analysis. Dawicke [5] and Seshadri et al [6,7] had found that using critical CTOA of 5.25 degrees and 5.00 degrees (measured $1 \mathrm{~mm}$ behind the crack tip) could best simulate the test results of for thin sheets of Al 2024-T3 loaded in LT and TL direction, respectively. Dawicke et al [8] also demonstrated that the crack tip conditions had a strong effect on the initial portion of stable tearing: the stress required to initiate crack growth is significantly higher for saw cut tips, compared to that of fatigue-generated crack tips. He also found that the initial tip conditions have little effect on the final failure stress in specimens with only a single large crack. The effects of the saw cut tips can be simulated in the STAGS code by entering a higher CTOA, $\Psi_{\text {ci }}$, for crack initiation. Once the crack is initiated from the saw cut, the normal value of critical CTOA, $\Psi_{c}$, is used for propagating the cracks. The saw cut angle, $\Psi_{\text {ci }}$, can be determined by correlating the measured crack initiation stress with the STAGS prediction. The saw cut angles were found to range from 5.7 degrees to 9.7 degrees with an average of 8.0 degrees for all twelve specimens tested. The saw cut angle simulation can also be used to predict the crack emerging from a fastener hole. By trial-and-error, it is found that, by using a saw cut angle of 12.00 degrees for the fastener holes while modeling the holes as slits, the residual strength of all four splice joint types predicted by STAGS compared very well with experimental results. Using 8.00 degrees for the saw cuts and 12 degrees for the fastener holes, the STAGS models were able to predict the stress levels for the crack initiation, link-up and residual strength for all specimens tested. Selected test results are as shown in Figures 2 The comparisons of crack initiation stress, first link-up stress and residual stress for all panels are plotted in Figure 3 The predicted stress has an average error of about 3\% for the first link-up, and an average error of $5 \%$ for the residual strength. A separate analysis was performed without using the saw cut angles for the panels with $1.3 \mathrm{~mm}$ and $2.5 \mathrm{~mm}$ MSD cracks. The predicted residual strengths were lower, but within 5\%, when compared to the 
one with saw cut angles.

\section{STIFFENED CURVED PANEL TEST SPECIMENS}

As part of the FAA's core capability, a unique, state-of-the-art Full-Scale Aircraft Structural Test Evaluation and Research (FASTER) facility has been established at the FAA William J. Hughes Technical Center for testing large curved panels representative of aircraft fuselage structure. This facility provides experimental data to support and validate analytical methods under development, including WFD prediction, repair analysis and design, and new aircraft design methodologies. As part of validation efforts four stiffened curved panels were tested using the FASTER facility as reported in [9]: two containing type 1 longitudinal skin splice, and the other two containing type 4 a circumferential skin splice joint. Each test specimen covered 6 frames by 7 longerons, and its overall size was approximately $3048 \mathrm{~mm} \mathrm{~L} \mathrm{x} 1727$ $\mathrm{mm} \mathrm{W}$ with a radius of $1676 \mathrm{~mm}$, as shown in Figure 4 The curved panels represented typical narrow body fuselage crown structure consisting of skin, frames, shear clips and longerons. One panel of each splice type contained only a large lead crack, and the other contained a lead crack and multiple site damages in the fastener holes ahead of the lead crack. The lead cracks were installed using a jeweler's saw and precracked to a predetermined length via fatigue cycles. For longitudinal splice panels, the lead crack at the beginning of the residual strength test was approximately $645 \mathrm{~mm}$ (total length). The central stiffeners and the shear clip directly above the lead crack were artificially severed. For circumferential splice joint panels, the lead crack at the beginning of the residual strength test was $483 \mathrm{~mm}$ long and the longeron splice fitting and intercoastal were also severed. The panel specimens were subjected to simulated cabin pressure, hoop and longitudinal loads simultaneously. The internal pressure was applied using water as the medium and the hoop and longitudinal loads were applied via servocontrolled actuators and a whiffletree load distributing system. The hoop loads were distributed between the skin and the frame at a predetermined ratio. The ratio between the hoop loads and the applied pressure was maintained at a constant throughout the test. The ratio between the nominal hoop stress and the nominal longitudinal stress is 1:0.5 and 1:1.3 for the panels containing longitudinal and circumferential splice joints, respectively. The applied loads, in terms of simulated cabin pressure, were incrementally applied until catastrophic failure occurred in the specimen. With an input CTOA of 12 degrees for the fastener holes without MSD cracks, the same as was used in the flat panel analyses, STAGS was able to predict the failure load with acceptable accuracy.

The predicted and measured data are shown in Figure 5 for CVP-1 and CVP-2, respectively. The predicted crack tearing compared very well with the test results up to $500 \mathrm{~mm}$ from the central frame. Beyond this length, STAGS predicted that the skin was capable of carrying higher loads once the crack had passed the adjacent frame. This prediction was based on the assumption that the adjacent frames remain intact throughout the analyses. A separate analysis was performed to determine the allowable of the frame, assuming that the frame would fail when the average stress in the frame cap reaches the ultimate allowable of the material. The frame allowable can then be estimated as follows: $P_{\text {applied }}\left(F_{t u} / \sigma_{\text {avg }}\right)$; where $\mathrm{P}_{\text {applied }}$ is the applied cabin pressure $(\mathrm{KPa})$ in the STAGS model; $\mathrm{F}_{\mathrm{tu}}$ is the material allowable, equal to $545 \mathrm{MPa}$ for the frame; and $\sigma_{\text {avg }}$ is the average stress of the elements at the frame cap in the direction parallel to the primary loading. The frame allowable curves are shown as solid lines in Figure 5. The intersecting point of the skin tearing curve and frame allowable curve represents the load level at which the stiffener and skin could fail simultaneously. Frame 
failure could bring about a complete failure of the whole test panel. Three residual strength tests were performed on the CVP-3 panel. The first two tests were terminated prematurely due to failures in the loading tabs of the test specimen. There was evidence indicating that one of the longeron near the crack tips could have been damaged during the second residual strength test. The extent of the damage was unclear. As expected, the predicted residual strength is higher than that of the experimental results. Otherwise, the predicted residual strength for the CVP-4 correlated very well with the experimental results.

\section{FULL SCALE AFT FUSELAGE PRESSURE BULKHEAD}

The test specimen was fabricated from a salvaged DC-9 Series 30 aft fuselage with 57,757 landings and 60,583 flight hours. The aft pressure dome web was made of 2014-T3 aluminum alloy with a nominal thickness of $1.0 \mathrm{~mm}$, which was attached to an outer ring via two rows of $4.0 \mathrm{~mm}$ diameter aluminum rivets $19 \mathrm{~mm}$ apart. The cross section of the joint is shown in Figure 6. A simulated primary damage $279 \mathrm{~mm}$ in length was introduced to the web at the first fastener row. Simulated MSD approximately $1.27 \mathrm{~mm}$ in size were introduced to the fastener holes in the projected path of the primary damage. The overall area with MSD and lead crack was approximately $914 \mathrm{~mm}$ long, located on the left side of the fuselage, $1016 \mathrm{~mm}$ above the cabin floor. The test specimen was mounted to a strongback and pressurized using regulated plant air to $53.8 \mathrm{KPa}$ several times for an initial strain survey. The specimen was then pressurized in small increments until failure occurred at approximately $62 \mathrm{KPa}$ at the aft pressure dome web. A STAGS finite element model was created for the residual strength analysis. The critical CTOA for the web material was analytically determined by selecting a CTOA that can best match the residual strength of a group of $\mathrm{M}(\mathrm{T})$ found in the published data [10] for Al 2014-T6 sheets. The best match angle was found to be $\mathrm{CTOA}=3.4$ degree for both constrained and unconstrained panels. The CTOA for the sawcut tip was estimated to be 6 degrees based on the relation for the sawcut tip and fatigue tip found for 2024-T3 aluminum. The comparison of predicted and measured data is shown in figure 7. The CTOA criterion that predicted the failure stress for narrow $\mathrm{M}(\mathrm{T})$ specimens also successfully predicted the residual strength of full-scale fuselage structure.

\section{CONCLUSIONS}

- The CTOA criterion is a relatively simple fracture parameter and can be easily applied to a complicated structure. However, considerable effort and resources are required to construct the finite element models and perform nonlinear analysis using STAGS.

- The estimated effects of the blunt tips of MSD introduced by wire cut on the residual strength of flat panels, based on STAGS analyses, is only about $5 \%$ higher than that with naturally generated fatigue crack tips.

- The prediction of residual strength on the aft pressure bulkhead containing a large lead crack and MSD was reasonably simulated using the critical CTOA derived from small $\mathrm{M}(\mathrm{T})$ coupons.

- The predicted stable tearing and residual strength are very sensitive to the critical value of CTOA used in the analysis. The present analysis shows that the critical CTOA derived by NASA's LaRC laboratory from simple M(T) test specimens for 2024-T3 can be successfully applied to riveted skin splice joints as tested under this study. 
- Stiffener failure often determines the residual strength of fuselage shell structures. The allowable stress of the stiffeners is very sensitive to the modeling techniques.

\section{REFERENCES}

1 Swift, T., "Widespread Fatigue Damage Monitoring-Issues and Concerns," Proceedings of 5th International Conference on Structural Airworthiness of New and Aging Aircraft, Federal Republic of Germany, DGLRBericht 93-02, 1993, pp. 133-150.

2 Rankin, C. C., Brogan, F. A., Loden, W. A., and Cabiness, H. D., "STAGS Users Manual," Lockheed Martin Missiles and Space Co. Inc., LMSC Report P032594, Version 3, March 1999.

3 Wells, A. A., "Crack Propagation Symposium Proceedings," Cranfield College of Aeronautics, 1961

4 Newman, J. C., Jr., (1984) "An Elastic-Plastic Finite Element Analysis of Crack Initiation, Stable Crack Growth, and Instability," Fracture Mechanics: Fifteenth Symposium, ASTM STP 833, pp93-117.

5 Dawicke, D. S., "Residual Strength Prediction Using a CTOA Criterion," FAA-NASA Symposium on Continued Airworthiness of Aircraft Structure, August 1996.

6 Seshadri, B. R., and Newman, J. C., Jr., "Residual Strength Analyses of Riveted Lap-splice Joints," NASA/ TM-2000-209856.

7 Seshadri, B. R., and Newman, J. C. "Analysis of Buckling and Stable Tearing in Thin-sheet Material," NASA/ TM-1998-208428.

8 Newman, J. C., Jr., Bigelow, C. A., and Dawicke, D. S., "Finite Element Analysis and Fracture Simulation in Thin-Sheet Aluminum Alloy," Proceedings of the International Workshop on Structural Integrity of Aging Airplanes, eds. Atluri, S. N., Harris, C. E., Hoggard, A., Miller, N., and Sampath, S. G., 1992, pp. 167-186.

9 Bakuckas, J. G., Jr., "Full-Scale Testing and Analysis of Fuselage Structure Containing Multiple Cracks," FAA Final Report, DOT/FAA/AR-01/46, July 2002.

10 Damage Tolerant Design Handbook, MCIC-HR-01R, 1983

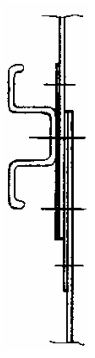

Type 1

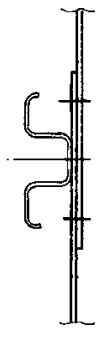

Type 2

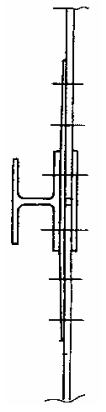

Type 3

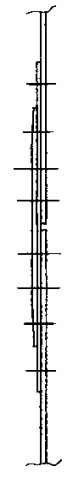

Type 4

Figure 1 - Cross Section of Four Fuselage Splice Joint

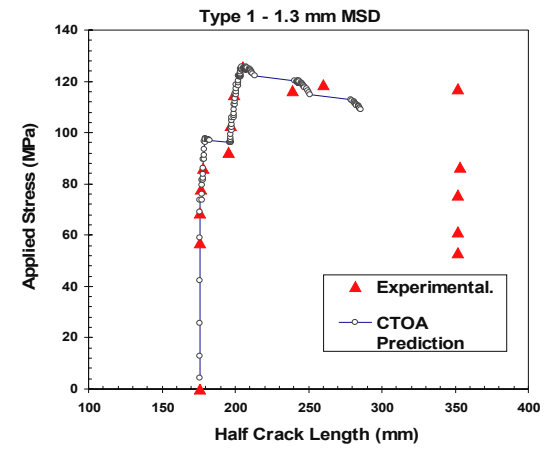

Figure 2 - Typical Measured Data vs. Prediction using STAGS

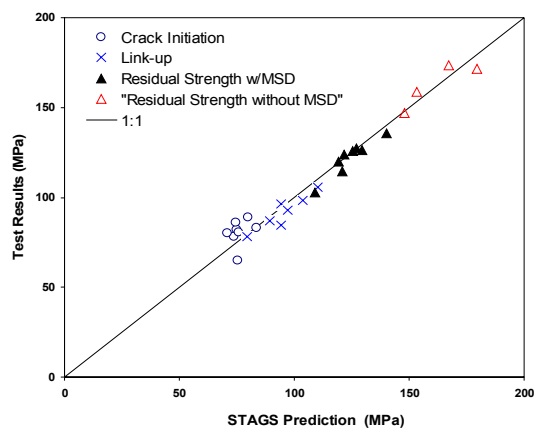

Figure 3 - Comparison of Measured and STAGS Predictions 


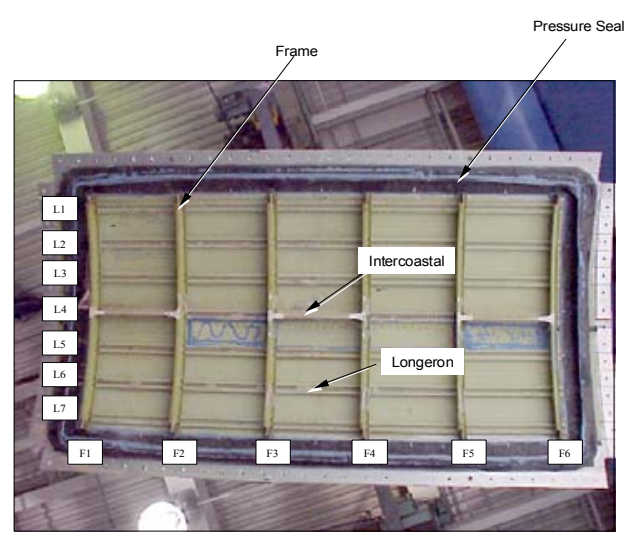

Figure 4- Curved Panel Test Specimen, CVP-1 Shown
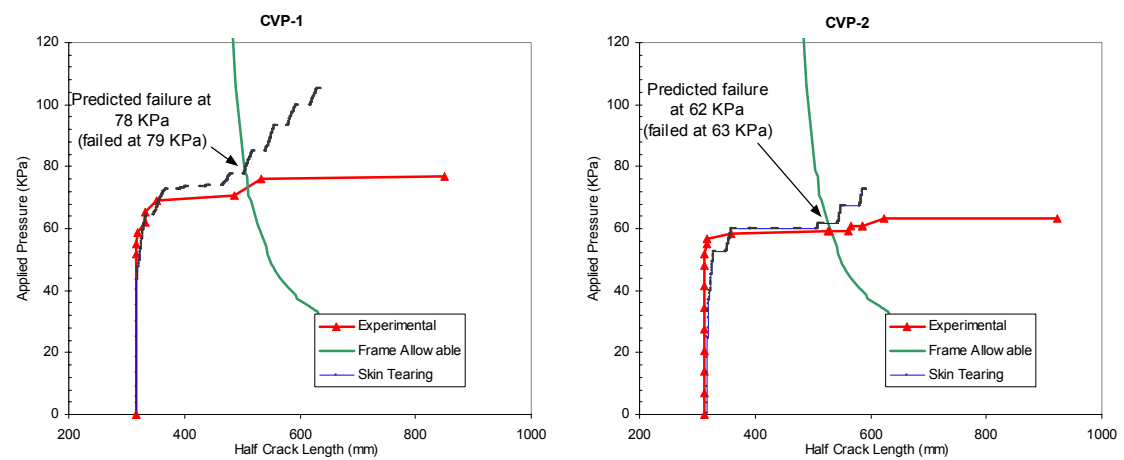

Figure 5- Comparison of Measured and STAGS Prediction for Curved Panel CVP-1 and CVP-2

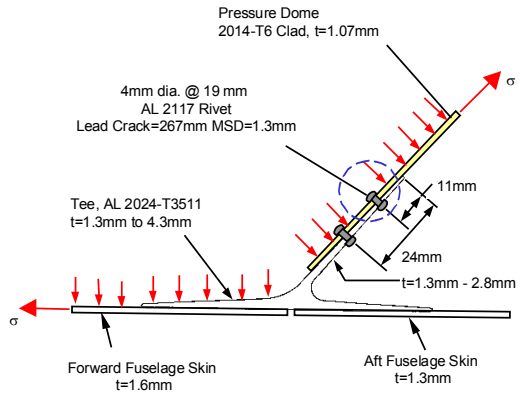

Figure 6- Cross Section of Aft Pressure Bulkhead

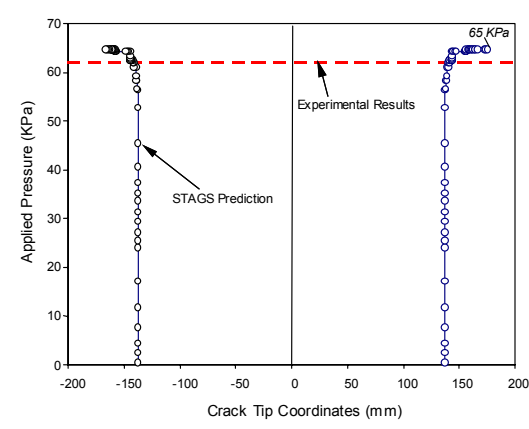

Figure 7-Comparison of Measured and STAGS Prediction for Aft Pressure Bulkhead 